\title{
Human Chymotrypsinogen B Production with Pichia pastoris by Integrated Development of Fermentation and Downstream Processing. Part 1. Fermentation
}

\author{
Simon Curvers, † Peter Brixius, † Thomas Klauser, ${ }^{\ddagger}$ J org Thommes, $\$$ \\ Dirk Weuster-Botz," Ralf Takors, ${ }^{*}, \dagger$ and Christian Wandrey ${ }^{\dagger}$
}

Institute of Biotechnology, Research Center J uelich, D-52425 J uelich, Germany, Mucos Pharma GmbH and Co., Markwiesenstrasse 55, D-72770 Reutlingen, Germany, and Institute of Enzyme Technology, Heinrich Heine Universität Duessel dorf, D-52426 J uelich, Germany

\begin{abstract}
Based on an integrated approach of genetic engineering, fermentation process development, and downstream processing, a fermentative chymotrypsinogen B production process using recombinant Pichia pastoris is presented. Making use of the $\mathrm{P}$. pastoris AOX1-promotor, the demand for methanol as the single carbon source as well as an inducer of protein secretion enforced the use of an optimized feeding strategy by help of on-line analysis and an advanced controller algorithm. By using an experimental system of six parallel sparged column bioreactors, proteolytic product degradation could be minimized while also optimizing starting conditions for the following downstream processing. This optimization of process conditions resulted in the production of authentic chymotrypsinogen at a final concentration level of $\mathbf{4 8 0}$ $\mathrm{mg} \cdot \mathrm{L}^{-1}$ in the whole broth and a biomass concentration of $150 \mathrm{~g} \cdot \mathrm{L}^{-1}$ cell dry weight, thus comprising a space-time yield of $5.2 \mathrm{mg} \cdot \mathrm{L}^{-1} \cdot \mathrm{h}^{-1}$. Alternatively to the high cell density fermentation approach, a continuous fermentation process was developed to study the effects of reduced cell density toward oxygen demand, cooling energy, and biomass separation. This devel opment led to a process with a highly increased spacetime yield of $25 \mathrm{mg} \cdot \mathrm{L}^{-1} \cdot \mathrm{h}^{-1}$ while reducing the cell dry weight concentration from 150 $\mathrm{g} \cdot \mathrm{L}^{-1}$ in fed-batch to $65 \mathrm{~g} \cdot \mathrm{L}^{-1}$ in continuous cultivation.
\end{abstract}

\section{Introduction}

The fermentative production of human chymotrypsinogen B (hCTRB), the inactive zymogen of the pancreatic serin-protease chymotrypsin (E.C. 3.4.21.1), was the focus of an integrated process development approach consisting of genetic engineering for recombinant Pichia pastoris strains, fermentation process devel opment in laboratory scale (30-L bi oreactor volume) and downstream processing. Fermentation development is presented in this paper, and downstream processing results are discussed in Part 2.

The target molecule chymotrypsin, common to all vertebrates in various isoforms, is widely used for analytical and preparative lysis or synthesis (1) of peptide bonds and as a drug in oral enzyme therapy. Examples of therapeutic drugs (2) are WobenzymN and WobeMugos (both by Mucos-Pharma, Geretsried, Germany) consisting of a combination of serin-proteases (trypsin, chymotrypsin) and plantal metalloproteases (e.g., papain, bromelain). Until now, chymotrypsin has been derived from animal pancreas, which makes the drug production dependent on the availability of bovine or porcine sources. A heterologous hCTRB production using recombinant Pichia pastoris strains could offer an unlimited access

\footnotetext{
† Institute of Biotechnology.

‡ Mucos Pharma GmbH \& Co.

$\S$ Institute of Enzyme Technology.

" Current address: Munich University of Technology, Chair of Biochemical Engineering, D-85748 Garching, Germany.
}

to the enzyme, yet no recombinant proteases have been applied to oral enzyme therapy.

The human chymotrypsinogen gene was first cloned by Tomita in 1989 (3) and further characterized by Hou in 1993 (4). The first successful expression of a chymotrypsin from rat was reported in 1996 by Venekei (5). The zymogen is activated to chymotrypsin by specific proteolysis by trypsin or, autocatalyticly, by active chymotrypsin. The preferential cleavage sites of chymotrypsin are the C-termini of tyrosine, tryptophane, phenylalanine and leucine.

The expression system $P$. pastoris has been chosen for the secretion of recombinant hCTRB, as it represents a powerful, still evolving expression system that was already successfully applied for recombinant protein production at unique levels $(6,7)$ as well as for biotransformation (8) of fine chemicals. Originally isolated for the production of single-cell protein, the discovery of the powerful AOX1-promotor and its use as an expression system by Cregg $(9,10)$ has led to a swift development of this system (11-13). Pichia combines a highly efficient secretion apparatus and the ability to grow to very high cell densities $\left(>150 \mathrm{~g} \mathrm{cdw} \cdot \mathrm{L}^{-1}\right)$ on simple mineral media with the ease of genetic manipulation using common tools. Furthermore, the isolation of the constituitive GAP promotor by Waterham in 1997 (14) and the FLD1 promotor, which is inducible by either methanol or methylamine, by Shen in 1998 (15) gave greater variability to Pichia-based expression. The vectors used for the transformation of $P$. pastoris integrate into the yeast 
genome, resulting stable expression strains ready for long-term cultivation.

All production strains used in this work have been constructed using the AOX-promotor $\left(\mathrm{P}_{\mathrm{AOX1}}\right)$ from $\mathrm{P}$. pastoris, originally controlling the expression of the enzyme alcoholoxidase. This enzyme catalyzes the first step in the oxidation of methanol in cells grown on this substrate as the sole carbon source, so the same regulatory genetic element is applied to the control of a major catabolic reaction and the expression of the desired product. By using this system, methanol acts as an inducer of heterologous protein production and simultaneously as the main substrate for cell growth.

As a result of relatively low recombinant protein/ substrate yields in yeast, high cell density fermentation is often favored to achieve high product titers (13). However, in combination with unlimited feeding of methanol, this process strategy leads to excessive oxygen consumption and heat dissipation that finally could exceed the capacities of production scale bioreactors. Beyond this, high biomass concentrations cause severe problems during downstream processing due to the filtration and separation behavior of the biomass. As a result significant product losses could occur.

Thus, it was the goal of this work to include downstream processing constraints cl osely in the fermentation process development. First an optimized fed-batch process was developed aiming to maximize the hCTRB concentration secreted by recombinant P. pastoris cells. Then this result was contrasted to the results of a continuous process development using the same production strain.

\section{Materials and Methods}

Yeast Strains and Plasmids. P. pastoris strains GS115 (his4), protease A-deficient SMD1168 (his4, pep4), and expression vector pHilS1 were obtained from I nvitrogen Corporation (Carlsbad, CA). The pHilS1 plasmid contains a HIS4 selectable marker, an AOX 1 promotorterminator cassette, and a Sacchar omyces cer evisae acid phosphatase secretion signal. The proCTRB hum $_{\text {gene was }}$ isolated from human pancreas. The genetic manipulation was done following standard procedures (16) and is not further described in this paper. The productions strains used for fermentation were kept in cryogenic vials at -80 ${ }^{\circ} \mathrm{C}$ in 33\% glycerol. Unless otherwise indicated, a GS115based strain containing a single copy of the ${ }_{\text {proC }} \mathrm{CTR}_{\text {hum }}$ gene fused to the described plasmid sequences was used.

On-Line and Off-Line Determination of Methanol Concentration. The methanol concentration during the cultivation was determined from the off-gas using either near-infrared spectrometric (Binos 4b2, Leybol d-Heraeus) or electrochemical (MC-168, PTI-Instruments) (17) measurements. The off-line measurement in the culture supernatant was done using a Chrompack 438A gas chromatograph with a 50 m FS-FFAP-CB column (CS$\mathrm{GmbH}$ ).

Determination of Biomass. The cell dry weight concentration (cdw) was determined as follows. An aliquot of the fermentation broth was spun down in an Eppendorff tube using a standard laboratory centrifuge at $13000 \mathrm{rpm}$. The pellet was then dried to constant weight and measured. If necessary, the bottom part of the pellet consisting of undissolved salts could be easily removed prior to weighing. The relation between volume of wet cells and cdw was determined to $3 \mathrm{~mL} \cdot \mathrm{g}^{-1}$. The relation between optical density and cdw measured during the fermentations proved to be nonlinear because of changing disturbance by antifoam agent and salt precipitations.

Determination of Product Titer. The product titer was determined spectrophotometrically by the activity of trypsin-activated chymotrypsin toward a chromogenic substrate, the synthetical peptide Suc-Ala-Ala-Pro-PhepNA (Bachem, Heidelberg). The colorless substate was cleaved at the C-terminus of phenylalanine, and the yellow chromophore p-nitroaniline released. Forty microliters of the adequately diluted sample was activated with $1 \mu \mathrm{L}$ of a trypsin solution $\left(1 \mathrm{mg} \cdot \mathrm{mL}^{-1}\right.$ in $1 \mathrm{mM} \mathrm{HCL}$ of porcine trypsin, Sigma) in $355 \mu \mathrm{L}$ of activation buffer (100 mM Tris- $\mathrm{HCl}, \mathrm{pH}$ 7,8, $20 \mathrm{mM}$ calcium chloride) for exactly $30 \mathrm{~min}$ at room temperature. Next, $40 \mu \mathrm{L}$ of the activated sample was further diluted in $1160 \mu \mathrm{L}$ of measurement buffer (activation buffer $+0.05 \%$ Triton $\mathrm{X}$ ) in a cuvette and equilibrated at $25^{\circ} \mathrm{C}$. The measurement was started by the addition of $200 \mu \mathrm{L}$ of substrate solution (2.1 mg Suc-Ala-Ala-Pro-Phe-pNA mL ${ }^{-1}$ activation buffer). The value of $\Delta \epsilon$ at $\lambda=406 \mathrm{~nm}$ was scanned for $1 \mathrm{~min}$ against air at $25^{\circ} \mathrm{C}$ in a spectrophotometer. The speed of pNA release was linear to hCTRB concentration as determined by calibration with purified chymotrypsinogen in the range from 20 to $100 \mathrm{mg} \cdot \mathrm{L}^{-1}$. The measured concentration in the culture supernatant was then calculated to the total volume of the fermentation broth using the relation of $3 \mathrm{~mL}$ wet volume per $\mathrm{g}$ cell dry weight.

Measurement of Proteolytic Activity in Culture Supernatants. The proteolytic activity in the culture broth was determined by the decomposition of azocasein (Sigma). The activity was quantified by calibration with Pronase from Streptomyces griseus as a reference protease. A total of $400 \mu \mathrm{L}$ of culture supernatant was mixed with $100 \mu \mathrm{L}$ of azocasein stock solution (10 mg azocasein $\mathrm{mL}^{-1}$ water) and incubated at $37^{\circ} \mathrm{C}$. After exactly $15 \mathrm{~min}$ the reaction was stopped by addition of $500 \mu \mathrm{L}$ TCA solution ( $10 \% \mathrm{w} / \mathrm{v}$ trichloracetic acid (Sigma)). The remaining undegraded azocasein was precipitated by the addition of TCA and subsequent incubation at $37^{\circ} \mathrm{C}$ for another $10 \mathrm{~min}$. The sample was then measured in a spectrophotometer at $\lambda=345 \mathrm{~nm}$. To eliminate any matrix influence on the absorption the sample was measured against the unprocessed sample, equivalently diluted with buffer (100 mM Tris- $\mathrm{HCl}, \mathrm{pH}$ 7.5, $100 \mathrm{mM}$ calcium chloride). The amount of azo dye liberated by decomposition of azocasein was equivalent to the proteol ytic activity in a range of $0.1-3.0 \mu \mathrm{g}$ Pronase $\mathrm{mL}^{-1}$, as determined by calibration with Pronase dissolved in the buffer described above. The measurement was not disturbed by the product chymotrypsinogen.

SDS-PAGE and Zymogram-PAGE . Electrophoresis was performed using an XCell II minicell (Novex) and precast gels of the same supplier according to the suppliers guidelines. For SDS-PAGE 12\% NuPage gels were used and all samples were reduced with DTT prior to electrophoresis. For zymogram analysis of active proteases $10 \%$ zymogram (gelatin) gels and $4-16 \%$ zymogram (blue casein) gels (both from Novex) were used, representing two different protease substrates.

Measurement of Oxygen Uptake Rate. The exhaust gas concentration of oxygen was measured paramagnetically with an oxygen analyzer (Oxynos 100, FisherRosemount). On the basis of the known oxygen concentration in the gas supply, the oxygen uptake rate could be subsequently calculated.

Estimation of Heat Generation. The heat formation caused by the disproportioning of methanol to carbondioxide and water via catabolic reactions and to biomass 
via an anabolic pathway was estimated from the reaction scheme as the free enthalpy of reaction under standard conditions.

The biomass yield $Y_{x / 5}$ was determined to $0.32 \mathrm{~g} \cdot \mathrm{g}^{-1}$ as an average value from all fermentations. Further, the composition of biomass grown on methanol was determined in a CHNS analyzer by the central department for chemical analysis, Research Center J uelich to be $\mathrm{C}_{1} \mathrm{H}_{1.68} \mathrm{O}_{0.61} \mathrm{~N}_{0.12}\left(\mathrm{M}=25.12 \mathrm{~g} \cdot \mathrm{C}-\mathrm{mol}^{-1}\right)$, a composition slightly differing from the formula $\mathrm{C}_{1} \mathrm{H}_{1.8} \mathrm{O}_{0.5} \mathrm{~N}_{0.2}$ used by Heijnen in 1997 (18).

By taking these values into consideration, the overall metabolism can be represented by the following reaction scheme: $\mathrm{CH}_{3} \mathrm{OH}+2.16\left(1 / 2 \mathrm{O}_{2}\right)+0.05 \mathrm{NH}_{3} \rightarrow 0.41$ $\mathrm{C}_{1} \mathrm{H}_{1.68} \mathrm{O}_{0.61} \mathrm{~N}_{0.12}+0.59 \mathrm{CO}_{2}+1.73 \mathrm{H}_{2} \mathrm{O}$. From this scheme, the free enthalpy of reaction can be calculated assuming standard conditions as $\Delta \mathrm{H}_{\mathrm{r}}{ }^{0}=\Sigma_{\mathrm{i}} v_{\mathrm{i}} \cdot \Delta \mathrm{H}_{\mathrm{f}}{ }^{0}(\mathrm{i})$ with $\Delta \mathrm{H}_{\mathrm{f}}{ }^{0}\left(\mathrm{CH}_{3} \mathrm{OH}\right)=-246 \mathrm{~kJ} \cdot \mathrm{mol}^{-1}, \Delta \mathrm{H}_{\mathrm{f}}{ }^{0}\left(\mathrm{C}_{1} \mathrm{H}_{1.68} \mathrm{O}_{0.61} \mathrm{~N}_{0.12}\right)=$ $-91 \mathrm{~kJ} \cdot \mathrm{mol}^{-1}, \Delta \mathrm{H}_{\mathrm{f}}{ }^{0}\left(\mathrm{NH}_{3}\right)=-133 \mathrm{~kJ} \cdot \mathrm{mol}^{-1}, \Delta \mathrm{H}_{\mathrm{f}}{ }^{0}\left(\mathrm{CO}_{2}\right)=$ $-394.1 \mathrm{~kJ} \cdot \mathrm{mol}^{-1}$ and $\Delta \mathrm{H}_{\mathrm{f}}{ }^{0}\left(\mathrm{H}_{2} \mathrm{O}\right)=-286 \mathrm{~kJ} \cdot \mathrm{mol}^{-1}(8)$ :

$$
\begin{aligned}
-Q=\Delta H_{r}{ }^{0}=\sum_{i} v_{i} \cdot \Delta H_{f}^{0}=(-1) \cdot(-246)+ \\
(-0.05) \cdot(-133)+0.41 \cdot(-91)+0.59 \cdot(-349.1)+ \\
17.3 \cdot(-286) \mathrm{kJ} \cdot \mathrm{mol}^{-1}=-485 \mathrm{~kJ} \cdot \mathrm{mol}^{-1}
\end{aligned}
$$

Calculated for $1 \mathrm{C}$-mol of biomass formed, this accounts for $\mathrm{Q}=1184 \mathrm{~kJ} \cdot \mathrm{C}-\mathrm{mol}^{-1}$, a value that is 3.5 -fold the heat balance for, e.g., the aerobic growth of Saccharomyces cerevisiae on glucose, which is calculated to be $339 \mathrm{~kJ}$. C-mol ${ }^{-1}$ of biomass (8).

Media Composition. MMG medium contained per liter $13.4 \mathrm{~g}$ of yeast nitrogen base w/o amino acids, $4 \times$ $10^{-4} \mathrm{~g}$ of biotin, and $20.0 \mathrm{~mL}$ of glycerol. Basal salts fermentation medium contained per liter $26.0 \mathrm{~mL}$ of phosphoric acid ( $85 \%), 0.6 \mathrm{~g}$ of calcium chloride dihydrate, $18.0 \mathrm{~g}$ of potassium sulfate, $14.0 \mathrm{~g}$ of magnesium sulfate heptahydrate, $4.0 \mathrm{~g}$ of potassium hydroxide, $50.0 \mathrm{~mL}$ of glycerol, $1.6 \times 10^{-3} \mathrm{~g}$ of biotin, and $8.0 \mathrm{~mL}$ of trace element solution. Glycerol feed medium contained per liter $500 \mathrm{~mL}$ of glycerol, $2.0 \times 10^{-3} \mathrm{~g}$ of biotin, and 10.0 $\mathrm{mL}$ trace element solution. Methanol feed medium contained per liter $2.0 \times 10^{-3} \mathrm{~g}$ of biotin and $10 \mathrm{~mL}$ of trace salt solution in pure methanol. Continuous fermentation feed medium contained per liter $197.5 \mathrm{~g}$ of methanol, 8.65 $\mathrm{mL}$ of phosphoric acid (85\%), $0.2 \mathrm{~g}$ of calcium chloride dihydrate, $6.0 \mathrm{~g}$ of potassium sulfate, $4.67 \mathrm{~g}$ of magnesium sulfate heptahydrate, $1.35 \mathrm{~g}$ of potassium hydroxide, $6.0 \mathrm{~mL}$ of ammonia solution (25\%), $1.0 \mathrm{~mL}$ of antifoam agent (AF 289, Sigma), $5.4 \times 10^{-3} \mathrm{~g}$ of biotin, and $2.7 \mathrm{~mL}$ of trace element solution. Trace element solution contained per liter $6.0 \mathrm{~g}$ of cupric sulfate pentahydrate, $0.08 \mathrm{~g}$ of potassium iodine, $3.0 \mathrm{~g}$ of manganese sulfate monohydrate, $0.2 \mathrm{~g}$ of sodium molybdate, $0.02 \mathrm{~g}$ of boric acid, $0.5 \mathrm{~g}$ of cobalt chloride, $20.0 \mathrm{~g}$ of zinc chloride, $65.0 \mathrm{~g}$ of ferrous sulfate heptahydrate, and 5.0 $\mathrm{mL}$ of sulfuric acid.

Fed-Batch Cultivation in Bioreactor with ClosedLoop Control of Methanol Concentration. Fed-batch fermentations were performed in a 30-L bioreactor (Che map, Volketsvil, Ch) equipped with standard controller circuits and on-line measurement of carbon dioxide, oxygen, and methanol in the exhaust gas. The vessel was filled with $10 \mathrm{~L}$ of basal salts fermentation medium and sterilized. The temperature was set at $25{ }^{\circ} \mathrm{C}$, aeration at $1 \mathrm{vvm}$, and agitation at $400 \mathrm{rpm}$. The $\mathrm{pH}$ was then adjusted to the desired starting value by addition of $25 \%$ ammonium hydroxide and inoculated with $1.75 \mathrm{~L}$ of a

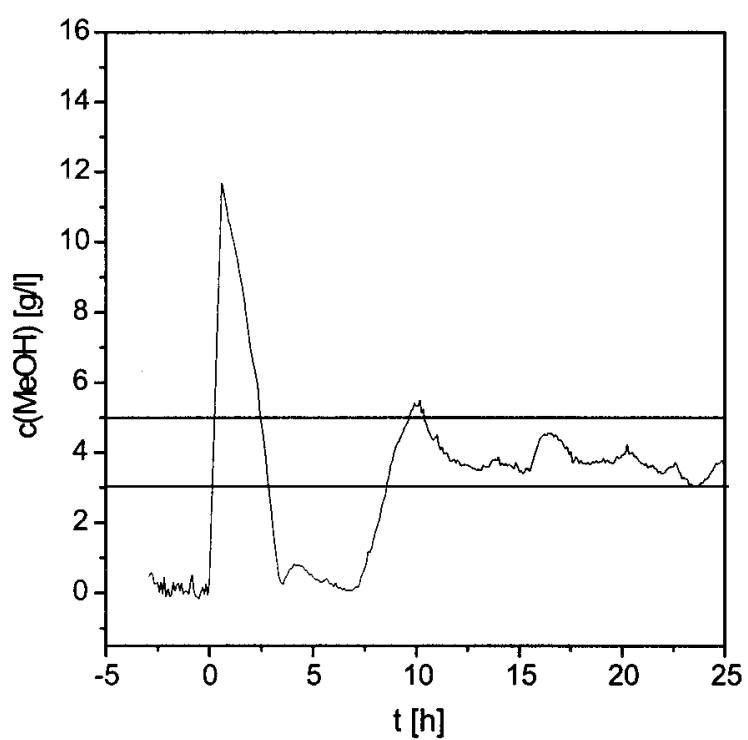

Figure 1. Real-time signal of methanol sensor during start of closed-loop control (at zero time) in a typical fed-batch fermentation run. As a result of the nonlinear response of the electrochemical sensor, the measurement is reliable only inside the indicated range. Values bel ow this range are indicated too low, values above are too high.

culture grown on MMG medium. The culture was grown in batch mode until depletion of glycerol. A constant feed of glycerol feed medium was then initiated for $4 \mathrm{~h}$ at 220 $\mathrm{mL} \cdot \mathrm{h}^{-1}$. After $4 \mathrm{~h}$, the cells were induced by addition of $4 \mathrm{~g} \cdot \mathrm{L}^{-1}$ methanol. During the entire fermentation, the methanol concentration was kept at $4 \mathrm{~g} \cdot \mathrm{L}^{-1}$ by adjusting the methanol-containing feed via closed-loop control. Methanol was measured by exhaust gas analysis as described and provided to a semi continuous Kalman filter (software tool, I nstitute of Biotechnology, J uelich, D) that estimated real-time methanol consumption rates. On the basis of these rates, a parameter adaptive minimalvariance controller (software tool) was used to cal culate corresponding methanol feeding rates. An example of the time course of the sensor signal in a typical fed-batch cultivation is given in Figure 1. All software tools were implemented in the process monitoring program MEDUSA, which has been developed at our institute. Further examples of this controlling approach were given by Weuster-Botz (19) in 1994. During the fermentation pressure, aeration, and agitation were gradually increased to $1.85 \mathrm{bar}, 37 \mathrm{I} \cdot \mathrm{min}^{-1}$, and $1150 \mathrm{rpm}$, respectively, to meet the oxygen requirements of the cell. When all of these parameters reached their maximum values, the further increase in oxygen consumption was met by automated addition of pure oxygen to the air supply. The concentration of dissolved oxygen was kept at 30\% saturation during the cultivation. Upon induction, the $\mathrm{pH}$ was allowed to drop to 3.0 to avoid proteolytic degradation of the product.

Cultivation in Parallel Small-Scale Bioreactors (Sparged Columns). For the examination of various fermentation parameters (e.g., pH, temperature), numerous test fermentations had to be carried out. To minimize overall time line for these investigations, an experimental system of six small-scale bioreactors $(200-400 \mathrm{~mL}$ reaction volume) was established (Figure 2 ). These sparged columns all owed a rapid screening of various fed-batch fermentation parameters. Each bioreactor could be equipped with automatic control of $\mathrm{pH}$ value and DO measurement. Temperature was controlled via a glass jacket connected to a bath thermostat, and the gas supply 


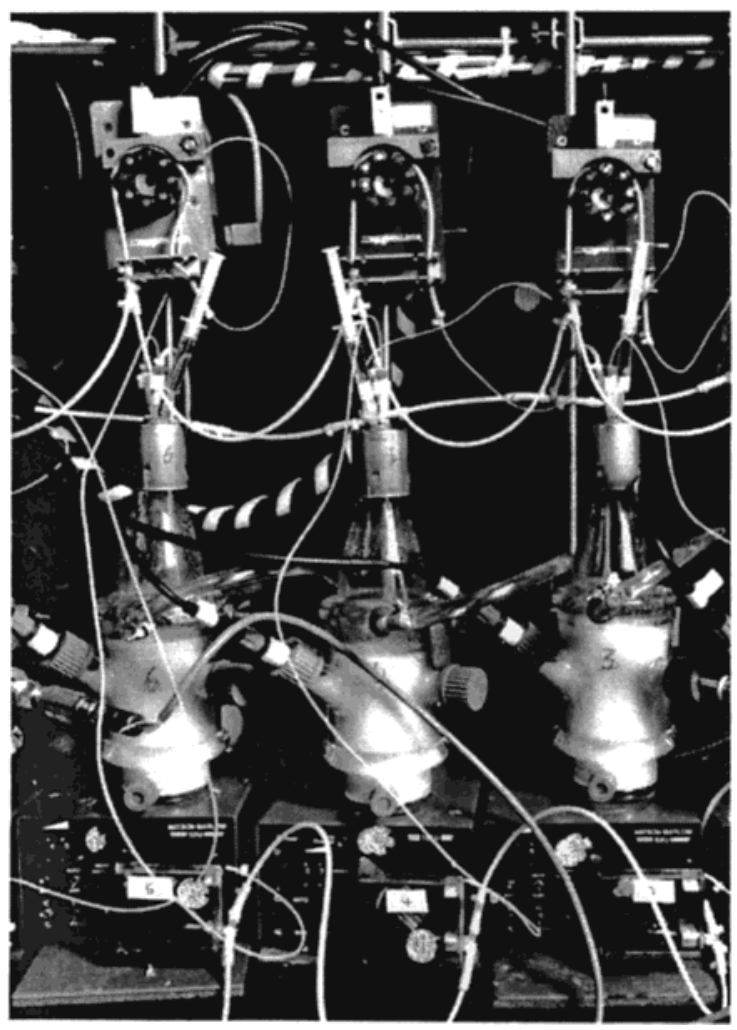

Figure 2. Three of six sparged columns, equipped with $\mathrm{pH}$ probe, DO probe (optional), and pumps for $\mathrm{pH}$ control and substrate feed as described.

(air/oxygen) was sparged through a sintered glass frit. To avoid excessive evaporation, the supply gas was saturated with water prior to sparging.

Upon depletion of glycerol, an intermittant methanol feed was initiated. A precalibrated, time-controlled pump dispensed $1 \mathrm{~mL}$ of methanol to the vessel within each dosing cycle with the duration of each cycle manually set by means of the oxygen-peak method (7). All fermentations were started at $\mathrm{pH} 5.0$ and the respective temperature for each experiment. After start of the methanol feed the $\mathrm{pH}$ was also set to the predefined value.

Continuous Cultivation with Closed-Loop Control of Methanol Concentration. Continuous fermentations were performed in a 7-L Chemap bioreactor at a reaction volume of $4 \mathrm{~L}$. The reactor was equipped identically to the described 30-L reactor, and the fermentations were started as described earlier. On depletion of glycerol the closed-loop control strategy as described above was used to control the preset methanol concentration during continuous cultivation. A steady state was achieved when important fermentation parameters such as biomass, methanol, and dissolved oxygen concentrations did not change significantly for the duration of five mean liquid residence times. The mean liquid residence time defined as $\tau=1 / D$ indicates the time interval during which the fermenter volume is fed into and drained from the fermenter once.

\section{Results and Discussion}

Effect of Culture Conditions and Choice of Production Strain on Proteolytic Activity and Product Decomposition. First results from shake-flask experiments (data not shown) suggested a temperature of 25.0 ${ }^{\circ} \mathrm{C}$ and a $\mathrm{pH}$ value of 5.5 for the production of recombinant human chymotrypsinogen $\mathrm{B}$ in $\mathrm{P}$. pastoris. Using these parameters in high cell density fermentation on
Table 1. Proteolytic Activity $\left[\mathrm{mg} \cdot \mathrm{L}^{-1}\right]$ in Culture Supernatants at End of Fed-Batch Fermentation in Sparged Columns; Determination of Proteolytic Activity in Units of Reference Protease Pronase from S. griseus

\begin{tabular}{lccc}
\hline & $25.0^{\circ} \mathrm{C}$ & $27.5^{\circ} \mathrm{C}$ & $30.0^{\circ} \mathrm{C}$ \\
\hline pH 3.0 & 0.00 & 1.70 & 2.38 \\
pH 4.0 & & flocculation & \\
pH 5.0 & 3.79 & 43.67 & 15.31 \\
pH 6.0 & 9.16 & 66.38 & 30.51
\end{tabular}

methanol resulted in significant proteolytic degradation. As shown in the coomassie-stained el ectropherogram in Figure 5, rows 4 to 7, almost no discrete protein bands were observable in the culture supernatant; the product of $26.5 \mathrm{kDa}$ was not at all visible. The samples taken from different times during the cultivation contain increasing amounts of contaminating proteins and degradation products. Proteolytic degradation of secreted proteins is frequently observed in Pichia fermentations, and various strategies have been developed to suppress proteolysis $(13,20)$, e.g., addition of casamino acids, variation of $\mathrm{pH}$, or use of protease-deficient Pichia strains. As the addition of complex media ingredients such as casamino acids was assumed to cause problems for downstream processing, the use of the protease-deficient strain SMD 1168 (pep ${ }^{-}$) and the optimization of $\mathrm{pH}$ and temperature during cultivation were favored to minimize proteolytic activity.

Using the same culture conditions as applied to GS115based Pichia strains, fermentations of protease-deficient SMD 1168-based strains resulted in increased purity of the culture supernatant but not in a significant decrease in the measured proteolytic activity. Decomposition of chymotrypsinogen was not completely avoi ded, and growth of the cells was poor in comparison to P. pastoris GS115based strains.

The influence of $\mathrm{pH}$ value and temperature during cultivation was investigated in a two-dimensional parameter lattice containing $\mathrm{pH}$ values of 2.0-7.0 and temperatures from 25.0 to $30.0^{\circ} \mathrm{C}$. At pH values of 2.0 and at 7.0 very poor growth and no product formation were observed, so these values could be neglected for further experiments. The remaining range of $\mathrm{pH} 3-6$ covers the typical range for Pichia fermentation (16), often a $\mathrm{pH}$ value of 3 results in a decreased decomposition of the target protein $(12,13)$. To minimize time effort, these experiments were performed in a parallel system of six small-size bioreactors as described.

All results showed a clear, reciprocal correlation between the measured proteolytic activity and the optically determined purity of the sample. It could also be shown that the optima of growth and proteolytic activity were similar. Therefore, the following discussion on the results will only refer to the measurements of proteolytic activity in the culture supernantant.

As shown in Table 1, significant effects of $\mathrm{pH}$ and temperature on the proteolytic activity could be observed. A maximum of proteolytic activity is indicated at 27.5 ${ }^{\circ} \mathrm{C}$. Regarding $\mathrm{pH}$ value, the proteolytic activity in the culture supernatant increased with higher $\mathrm{pH}$. At pH 3.0 and $25.0^{\circ} \mathrm{C}$, no proteolytic activity could be detected in culture supernatants and the product was detected as a sharp, single band in SDS-PAGE. As a consequence, optimal culture conditions for the production of hCTRB were identified at $\mathrm{pH} 3.0$ and $25^{\circ} \mathrm{C}$.

Since the optima for growth and proteolytic activity were similar, an optimal set of parameters must be a compromise between the optimization of growth rate and the minimization of proteolytic activity.

An interesting phenomenon occurred in the $\mathrm{pH}$ range of approximately 3.3 to 4.5. As shown in Figure 3, the 


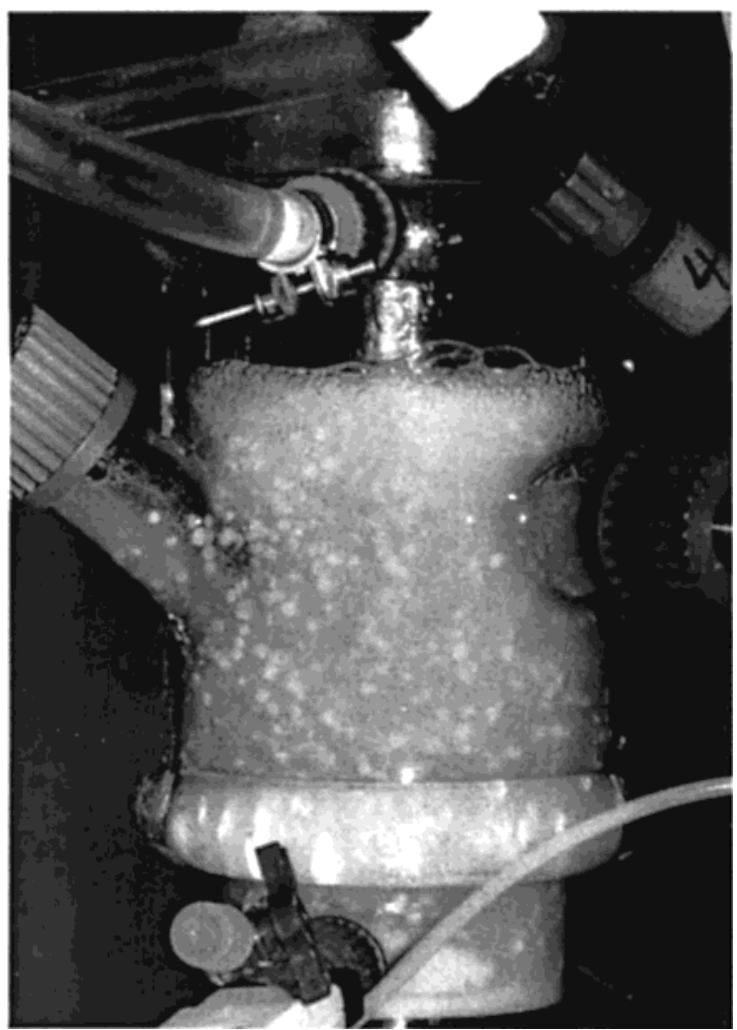

Figure 3. Flocculating Pichia cells at $\mathrm{pH} 4$ in a sparged col umn bioreactor. The cells form pellets of up to $3 \mathrm{~mm}$ in diameter.

cells started to form aggregates up to $3 \mathrm{~mm}$ in diameter. This coincided with a significant reduction of growth, substrate uptake, and oxygen consumption, probably caused by the reduction of the cell/medium interphase. The effect of flocculation was fully reversible by $\mathrm{pH}$ shift in any direction and reproducible by a backshift into the critical range. The effect could also be reproduced in stirred laboratory bioreactors, although it was not as prominent as in the sparged columns because of the much higher sheer stress in a stirred tank reactor. On account of the observed flocculation, the $\mathrm{pH}$ range of 3.5-4.5 was not considered for further cultivations. Still, this phe nomenon might offer interesting approaches to cell separation.

Attempts to identify the enzymes responsible for proteolytic activity by $\mathrm{N}$-terminal protein sequencing failed. However, zymogram analysis of cultivation supernatants suggested the presence of at least two different proteases showing no activity toward the chymotrypsin-specific substrate Suc-Ala-Ala-Pro-Phe-pNA. One of these proteases with a molecular weight of approximately $50 \mathrm{kDa}$ showed no activity toward (blue) casein or azocasein but was able to hydrolyze gelatine in zymogram gels, while the other enzyme with a molar weight of $>200 \mathrm{kDa}$ hydrolyzed casein but was not seen in gelatine-based zymogram gels. Both molecular weights could not be identified in comassie-stained SDS-PAGE gels. The activity of both proteases in culture supernatants from fermentation at high $\mathrm{pH}$ value towards all tested substrates including chymotrypsinogen was irreversibly inactivated by titration of the culture supernatant to a $\mathrm{pH}$ value of 3, accompanied by a heavy precipitation of protein. This precipitation did not include intact chymotrypsinogen, which is fully soluble and stable at this $\mathrm{pH}$.

Development of an Optimized Fed-Batch Process Using a Closed-Loop Controlled Methanol Feeding Strategy. Using the optimized $\mathrm{pH}$ and temperature

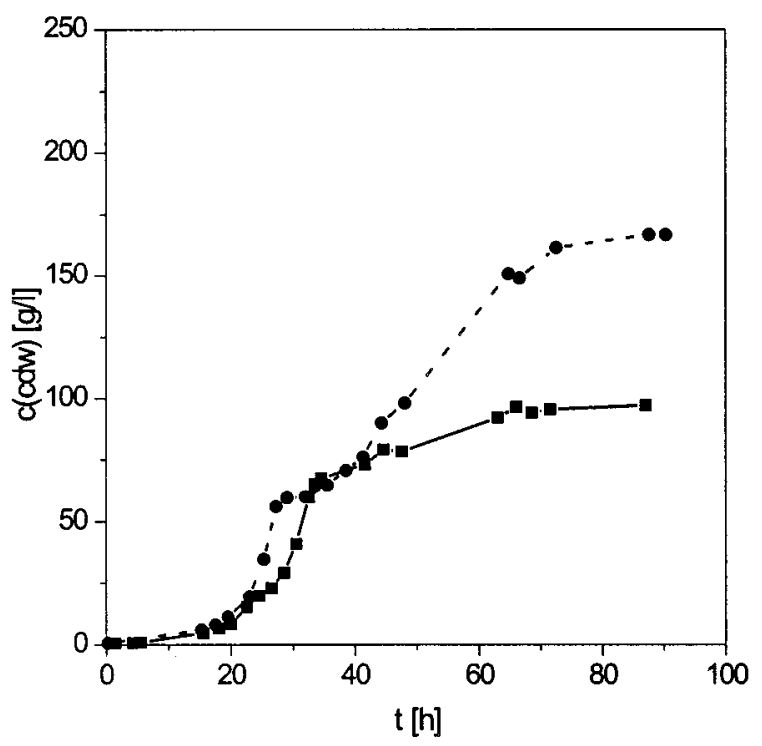

Figure 4. Development of biomass concentration (cell dry weight) during cultivation under methanol-limited conditions (घ, solid line) compared to cultivation with closed-loop control of methanol concentration ( $\bullet$, dashed line).

conditions, a fed-batch cultivation was devel oped for the production of recombinant hCTRB. It could be shown, that the cultivation in a methanol unlimited mode (methanol concentration was controlled at $4 \mathrm{~g} \cdot \mathrm{L}^{-1}$ ) yiel ded much higher growth and product formation (Figure 4) than the methanol-limited process $(7,13)$. The methanol concentration of $4 \mathrm{~g} \cdot \mathrm{L}^{-1}\left({ }^{2} 0.5 \% \mathrm{v} / \mathrm{v}\right)$ was chosen as this concentration is typically applied to shake flask expressi on (11). The advantages of unlimited methanol feeding have also been proved earlier $(17,21,22)$.

The $\mathrm{pH}$ shift from 5.5 to 3.0 during induction resulted in an increase of space-time yield from $2.1 \mathrm{mg} \cdot \mathrm{L}^{-1} \cdot \mathrm{h}^{-1}$ (188 $\mathrm{mg} \cdot \mathrm{L}^{-1} / 92 \mathrm{~h}$ ) to $5.3 \mathrm{mg} \cdot \mathrm{L}^{-1} \cdot \mathrm{h}^{-1}\left(470 \mathrm{mg} \cdot \mathrm{L}^{-1} / 92 \mathrm{~h}\right)$ and a decrease of corresponding growth rates. Still, very high biomass concentrations ( $150 \mathrm{~g} \cdot \mathrm{L}^{-1} \mathrm{cdw}$ after $92 \mathrm{~h}$ at $\mathrm{pH} 3$ and $170 \mathrm{~g} \cdot \mathrm{L}^{-1} \mathrm{cdw}$ at $\mathrm{pH}$ 5.5) were achieved. Figure 6 shows the development of biomass and product titer compared for the fermentations at pH 5.5 and 3.0. The culture supernatants from the optimized fermentation at pH 3.0 contained only one major protein fraction in comparison to the highly contaminated supernatants from $\mathrm{pH} 5.5$ fermentation (Figure 5, rows 4-7, $\mathrm{pH}$ 5.5; rows $9-12, \mathrm{pH} 3.0$ ).

As demonstrated in Part 2 of this publication, the results from downstream processing development indicated a pH optimum for the product purification identical to the value identified for fermentation.

Despite these improvements, this high cell density process would still cause problems, should it be scaled up to industrial scale. The first problem is the excessive consumption of oxygen by Pichia when grown on methanol. As shown above, it requires $1.08 \mathrm{~mol}$ of $\mathrm{O}_{2}$ to metabolize $1 \mathrm{~mol}$ of methanol. This resulted in measured oxygen uptake rates (OUR) up to $2000 \mathrm{mmol} \cdot \mathrm{L}^{-1} \cdot \mathrm{h}^{-1}$ in nonoptimized fermentations at $\mathrm{pH}$ 5.5. As a result of growth rate reduction at $\mathrm{pH} 3.0$, this could be reduced to an OUR of $790 \mathrm{mmol} \cdot \mathrm{L}^{-1} \cdot \mathrm{h}^{-1}$, which still represents a high value.

In an industrial scale STR a maximum oxygen transfer rate of significantly below $300 \mathrm{mmol} \cdot \mathrm{L}^{-1} \cdot \mathrm{h}^{-1}$ can be realized using air. The use of especially developed airlift fermenters allows a maximum OTR of up to 309 $\mathrm{mmol} \cdot \mathrm{L}^{-1} \cdot \mathrm{h}^{-1}(23)$. Thus, the very high oxygen demand of $\mathrm{P}$. pastoris during growth on methanol requires 


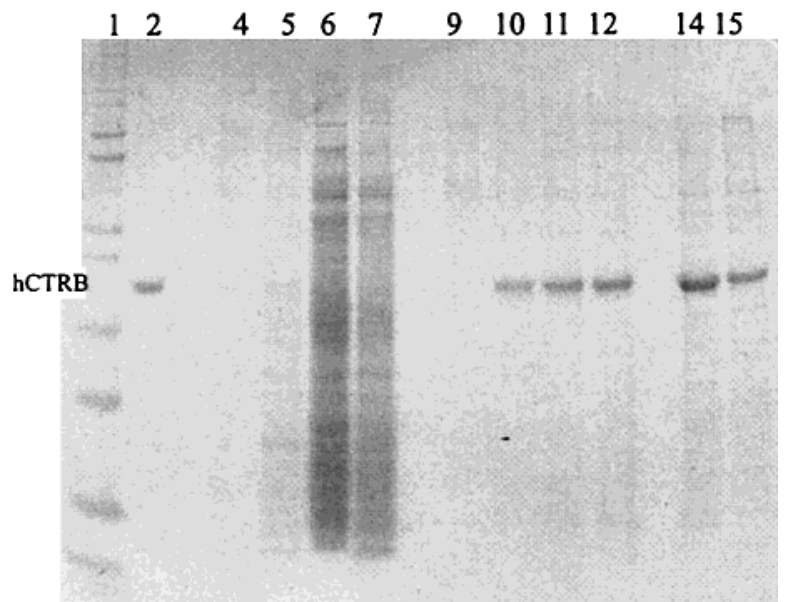

Figure 5. SDS-PAGE (12\%) of culture supernatants from Pichia pastoris hCTRB fermentation: row 1, Mark 12 size marker; row 2, hCTRB standard $100 \mathrm{mg} \cdot \mathrm{L}^{-1}$; rows 4-7, fedbatch fermentation $\mathrm{pH} 5.5$, preinduction, 18, 42, $62 \mathrm{~h}$ induction; row 9-12, fed-batch fermentation $\mathrm{pH} 3.0$, preinduction, 18, 42, $62 \mathrm{~h}$ induction. hCTRB indicates the molar weight of the product, $26.5 \mathrm{kDa}$.

supplementation of pure oxygen to the bioreactor. Be cause of cost and safety considerations the application of pure oxygen, especially in combination with the highly flammable substrate methanol, might be a problem in industrial large-scale fermentation.

Furthermore, the microbial heat formation would require high cooling costs in production bioreactors. On the basis of the aforementioned estimation method, a heat generation of $\mathrm{Q}=485 \mathrm{~kJ} \cdot \mathrm{mol}^{-1}$ methanol consumed was calculated. In the optimized fermentation the maximum methanol uptake was determined to approximately $25 \mathrm{~g} \cdot \mathrm{L}^{-1} \cdot \mathrm{h}^{-1}\left(=0.78 \mathrm{~mol} \cdot \mathrm{L}^{-1} \mathrm{~h}^{-1}\right)$, resulting in a heat generation of $413 \mathrm{~kJ} \cdot \mathrm{L}^{-1} \cdot \mathrm{h}^{-1}\left(106 \mathrm{~W} \cdot \mathrm{L}^{-1}\right)$.

Therefore, an alternative fermentation approach avoiding the necessity of oxygen enrichment to the process air was developed.

Production of Recombinant Human Chymotypsinogen in Continuous Cultivation. Alternatively to the fed-batch approach, studies were carried out to develop a continuous fermentation process aiming to reduce necessary oxygen uptake rates while maintaining or even improving space-time yields (STY). Under steady-state conditions, biomass concentration is a function of dilution rate and input substrate concentration and therefore can be chosen freely to adapt the process to any given oxygen transfer rate (OTR). Continuous fermentations were performed using a methanol concentration of $197.5 \mathrm{~g} \cdot \mathrm{L}^{-1}$ $(25 \% \mathrm{v} / \mathrm{v})$ in the feed medium resulting in a cell dry weight of $65 \mathrm{~g} \cdot \mathrm{L}^{-1}$ in steady state. The methanol concentration was maintained at a constant value using the same closed-loop control strategy as described for the fedbatch cultivation. Figure 7 shows space-time yields and oxygen uptake rates of three steady states using the same strains and the same conditions as in the optimized fedbatch cultivation. In comparison to the results of the optimized fed-batch fermentation, at a methanol concentration of $0.78 \mathrm{~g} \cdot \mathrm{L}^{-1}$ a 4.7 -fold increase in space-time yield to $25 \mathrm{mg} \cdot \mathrm{L}^{-1} \cdot \mathrm{h}^{-1}$ concurrently with a 2.3 -fold reduction of biomass concentration was achieved. As a consequence of biomass reduction, the oxygen uptake rate was significantly reduced, so that the concentration of dissolved oxygen could be maintained without supplementation of pure oxygen.

Heterologous protein production based on AOX1 promotor with methanol as the only carbon source is
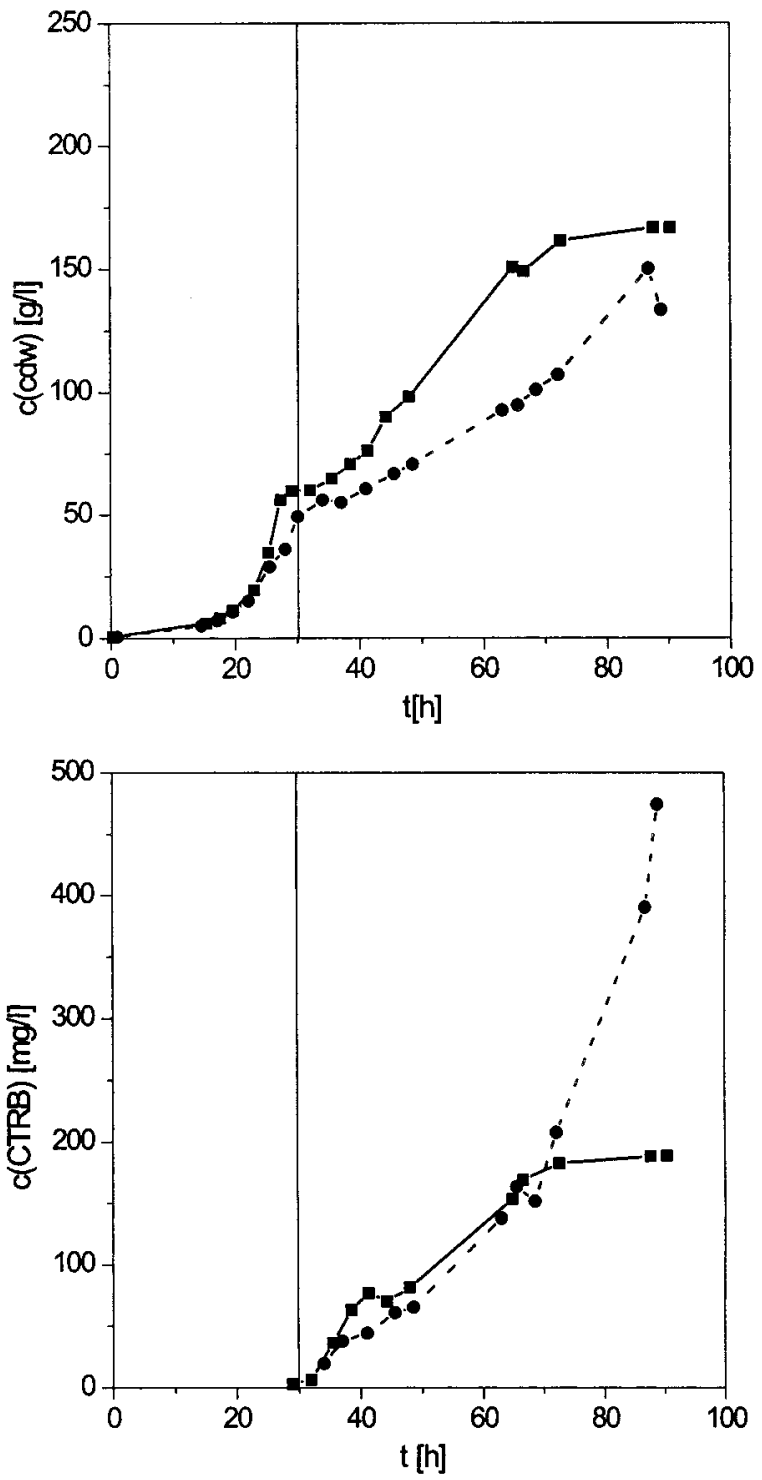

Figure 6. Cell dry weight (left) and product (right) titer in fedbatch cultivations at ph values of 5.5 ( $\mathbf{\square}$, solid lines) and 3.0 (• dashed lines), respectively. The horizontal lines represent the time of induction by changing the carbon source from glycerol to methanol.

considered to be mainly growth-coupled so that the increased growth rate during continuous cultivation inevitably will give rise to higher productivity. Another reason for this dramatically increased STY has to be seen in the prolonged production phase, which allows the growth phase without any product formation to be disregarded. In the fed-batch fermentation, no product is formed during one-third of the entire process.

Beyond these explanations, cell age distribution in the culture could also influence space-time yield. In contrast to procaryotic cells, yeast cells show signs of aging and senescence. It has been shown for S. cerevisiae (24) that budding yeast cells undergo severe phenotypic changes from the juvenile bud to a senescent cell. One main symptom for cell senescence is a continuous decrease in the speed of metabolism and cell cycle until cell death. Obviously, a senescent cell will contribute less to protein production than a juvenile one. In fed-batch cultivation, all cells remain in the system, so that senescent cell accumulate during the fermentation while in continuous cultivation old cells are washed out. As a consequence, 


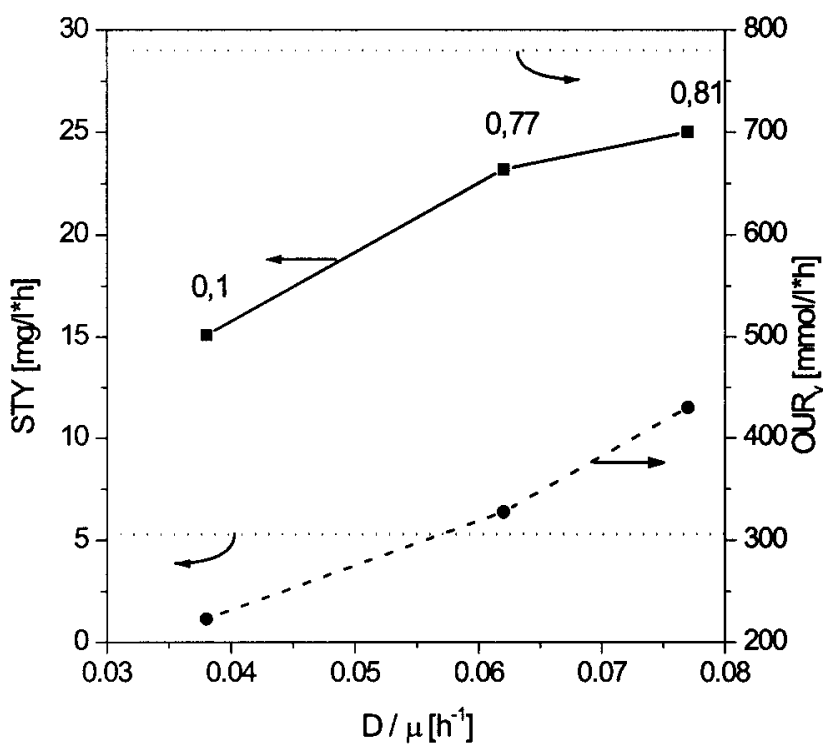

Figure 7. Space-time yields ( $\mathbf{\square}$, solid line) and oxygen uptake rates $(\bullet$, dashed line) of three different steady states in relation to the growth rate. The numbers indicate the corresponding methanol concentrations. The dotted lines represent the respective values from fed-batch cultivation.

the mean cell age in steady state corresponds to the dilution rate of the reactor.

The strain used for all fermentations was phenotypically stable unless the methanol concentration did not reach toxic levels. A transient exposure to toxic methanol levels led to an immediate and complete breakdown of productivity of the culture, although growth could be fully restored during prolonged fermentation. In fact, this loss of productivity led to an increase of $\mu_{\max }$ from approximately 0.8 to $>0.13$, the all owed maximum dilution rate, thus indicating reversion of the cells to wild-type growth characteristics. The critical concentration could not yet be determined precisely but is assumed to be bel ow $20 \mathrm{~g} \cdot \mathrm{L}^{-1}$. In fed-batch fermentations Zhang (22) identified a critical methanol concentration of $3.65 \mathrm{~g} \cdot \mathrm{L}^{-1}$ for the production of the heavy-chain fragment $C$ of Botulinum neurotoxin. Higher concentrations led to a significant reduction in growth.

Nevertheless, successful fermentations of more than $1000 \mathrm{~h}$ duration demonstrated the stability of the recombinant microbial system as well as the stability of the total fermentation process.

\section{Conclusions}

It can be concluded that $P$. pastoris is a suitable host for the expression of recombinant human chymotrypsinogen $B$ by fed-batch or continuous fermentation using closed-loop control of methanol concentration.

Proteolytic degradation of the product chymotrypsinogen $B$ during fed-batch operation could be avoided by changing the $\mathrm{pH}$ value from 5.5 to 3.0, resulting in an improvement in space-time yield from 2.1 to $5.3 \mathrm{mg}$. $\mathrm{L}^{-1} \cdot \mathrm{h}^{-1}$. The application of a continuous approach yiel ded a further improvement to a space-time yield of 25 $\mathrm{mg} \cdot \mathrm{L}^{-1} \cdot \mathrm{h}^{-1}$. At the same time the cdw concentration was reduced to only $65 \mathrm{~g} \cdot \mathrm{L}^{-1}$, compared to $>150 \mathrm{~g} \cdot \mathrm{L}^{-1}$ in fedbatch fermentation. Space-time yields from the different approaches are compared in Figure 8.

The development of fermentation processes was performed in close contact with development of product recovery protocols. As a result of this integrated approach, the fermentation broths could readily be trans-

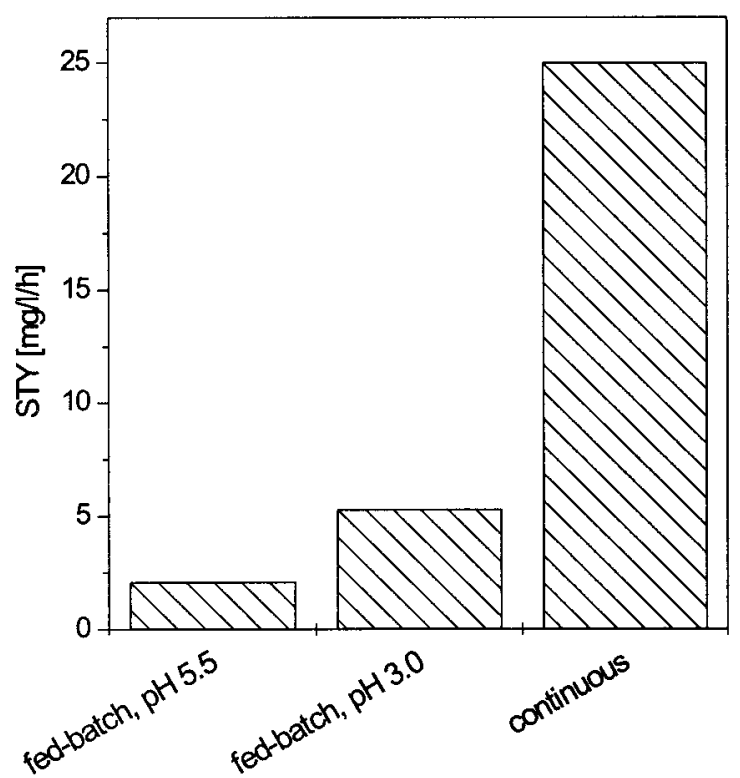

Figure 8. Space-time yields for fed-batch cultivation at $\mathrm{pH} 5.5$ and pH 3.0 compared to a sel ected steady state from continuous cultivation.

ferred to downstream processing without major adjustments of, e.g., $\mathrm{pH}$ or conductivity.

\section{Notation}

$\begin{array}{ll}\text { AOX1 } & \text { alcoholoxidase } 1 \\ \text { cdw } & \text { cell dry weight }\left[\mathrm{g} \cdot \mathrm{L}^{-1}\right] \\ \text { D } & \text { dilution rate }\left[\mathrm{h}^{-1}\right] \\ \text { hCTRB } & \text { human Chymotrypsinogen B } \\ \text { OUR } & \text { oxygen uptake rate }\left[\mathrm{mmol} \cdot \mathrm{L}^{-1} \cdot \mathrm{h}^{-1}\right] \\ \text { PAOX1 } & \text { promotor from } \mathrm{P} . \text { pastoris al cohol oxidase } 1 \\ \text { Q } & \text { heat dissipation }\left[\mathrm{kJ} \cdot \mathrm{C}-\mathrm{mol}^{-1}\right] \\ \text { STR } & \text { stirred tank reactor } \\ \text { STY } & \text { space-time yield }\left[\mathrm{mg} \cdot \mathrm{L}^{-1} \cdot \mathrm{h}^{-1}\right] \\ \text { Y } & \text { yield coefficient }\left[\mathrm{g} \cdot \mathrm{g}^{-1}\right] \\ \mu & \text { growth rate }\left[\mathrm{h}^{-1}\right]\end{array}$

\section{Acknowledgment}

This work was founded by the German Federal Ministry of Education, Science, Research and Technology (BMBF), grant 0311413.

\section{References and Notes}

(1) Levitsky, V.; Lozano, P.; I borra, J . L. Glycosylated $\alpha$-chymotrypsin as a catalyst for kyotorphin synthesis in waterorganic media. Biotechnol. Lett. 1999, 21, 595-599.

(2) Kleine, M. W. Introduction to oral enzyme therapy. Int. J . Immunother. 1997, 13, 59-65.

(3) Tomita, N.; Izumoto, Y.; Horii, A.; Doi, S.; Yokouchi, H.; Ogawa, M.; Mori, T.; Matsubara, K. Molecular doning and nucleotide sequence of human pancreatic prechymotrypsinogen cDNA. Biochem. Biophys. Res. Comm. 1989, 158, 569575.

(4) Hou, D. X.; Ozawa, K.; Tomita, N.; Maeda, Y.; Hashiguchi, T.; Yokoyama, K.; Soeda, E. Genomic cloning and partial characterization of human chymotrypsinogen gene. J pn. J . Human Genet. 1993, 38, 371-380.

(5) Venekei, I.; Graf, L.; Rutter, W. J. Expression of rat chymotrypsin in yeast: A study on the structural and functional significance of the chymotrypsinogen propeptide. FEBS Lett. 1996, 379, 139-142. 
(6) Werten, M. W. T.; VandenBosch, T. J .; Wind, R. D.; Mooibroek, H.; DeWolf, F. A. High-yield secretion of recombinant gelatins by Pichia pastoris. Yeast 1999, 15, 10871096.

(7) Clare, J . J .; Romanos, A. M.; Rayment, F. B.; Rowedder, J . E.; Smith, M. A.; Payne, M. M.; Sreekrishna, K.; Henwood, C. A. Production of mouse epidermal growth factor in yeast: high-level secretion using Pichia pastoris strains containing multiple gene copies. Gene 1991, 105, 205-212.

(8) Wu, S.; Fallon, R. D.; Payne, M. S. Engineering Pichia pastoris for stereoselective nitrile hydrolysis by coproducing three hetereologous proteins. Appl. Microbiol. Biotechnol. 1999, 52, 186-190.

(9) Cregg, J . M.; Barringer, K. J .; Hessler, A. Y.; Madden, K. R. Pichia pastoris as a host system for Transformation. Mol . Cell. Biol. 1985, 5, 3376-3385.

(10) Cregg, J . M.; Madden, K. R. Development of the methylotrophic yeast, Pichia pastoris, as a host system for the production of foreign proteins. Dev. Ind. Microbiol. 1988, 29 , 33-41.

(11) Cregg, J. M.; Vedvick, T. S.; Raschke, W. C. Recent advances in the expression of foreign genes in Pichia pastoris. Bio/ Technology 1993, 11, 905-910.

(12) Cregg, J . M. Expression in the methylotrophic yeast Pichia pastoris. In Gene Expression Systems: Using Nature for the Art of Expression; Fernandez, J. M.; Hoeffler, J. P., Eds.; Academic Press: San Diego, London, 1999; pp 157-191.

(13) Sreekrishna, K.; Kropp, K. E. Pichia pastoris. In Nonconventional Yeasts in Biotechnology: A Handbook; Wolf, K., Ed.; Springer: Berlin, Heidel berg, New York, 1996; pp 293-311.

(14) Waterham, H. R.; Digan, M. E.; Koutz, P. J .; Lair, S. V.; Cregg, J. M. I solation of the Pichia pastoris glyceraldehyd3-phospate dehydrogenase gene and regulation and use of its promotor. Gene 1997, 186, 37-44.

(15) Shen, S.; Sulter, G.; J effries, T. W.; Cregg, J . M. A strong nitrogen source-regulated promotor for controlled expression of foreign genes in the yeast Pichia pastoris. Gene 1998, 216, 93-102.

(16) Lin Cereghino, J.; Cregg, J. M. Heterologous protein expression in the methylotrophic yeast Pichia pastoris. FEMS Microbiol. Rev. 2000, 24, 45-66.

(17) Katakura, Y.; Zhang, W.; Zhuang, G.; Omasa, T.; Kishimoto, M.; Goto, Y.; Suga, K. Effect of methanol concentration on the production of human $\beta(2)$-glycoprotein I domain $\mathrm{V}$ by a recombinant Pichia pastoris: A simple system for the control of methanol concentration using a semiconductor gas sensor. J . Ferment. Bioeng. 1998, 86, 482-487.

(18) Heijnen, J J J . A thermodynamically based description of chemotrophic microbial growth stoichiometry and kinetics, In Encyclopedia of Bioprocess Technology: Fermentation, Biocatalysis and Bioseparation; Flickinger, M. C., Drew, S. W., Eds.; J ohn Wiley: New York, 1997.

(19) Weuster-Botz, D.; Paschold, H.; Striegel, B.; Gieren, H.; Kula, M.-R.; Wandrey, C. Continuous computer controlled production of formate dehydrogenase $(\mathrm{FDH})$ and isolation on a pilot scale. Chem. Eng. Technol. 1994, 17, 131-137.

(20) Sreekrishna, K.; Brankamp, R. G.; Kropp, K. E.; Blankenship, D. T.; Tsay, J. T.; Smith, P. L.; Wierschke, J. D.; Subramaniam, A.; Birkenberger, L. A. Strategies for optimal synthesis and secretion of heterologous proteins in the methylotrophic yeast Pichia pastoris. Gene 1997, 190, 5562.

(21) Guarna, M. M.; Lesnicki, G. J .; Tam, B. M.; Robinson, J .; Radziminski C. Z.; Hasenwinkle, D.; Boraston, A.; J ervis, E.; MacGillivray, R. T. A.; Turner, R. F. B.; Kilburn, D. G. Online monitoring and control of methanol concentration in shake-flask cultures of Pichia pastoris. Biotechnol. Bioeng. 1997, 56, 279-286.

(22) Zhang, W.; Bevins, M. A.; Plantz, B. A.; Smith, L. A.; Meagher, M. M. Modelling Pichia pastoris growth on methanol and optimizing the production of a recombinant protein, the heavy-chain fragment $C$ of botulinum neurotoxin, serotype A. Biotechnol. Bioeng. 2000, 70, 1-8.

(23) Ichii, T.; Takehara, S.; Konno, H.; Ishida, T.; Sato, H.; Suzuki, A.; Yamazumi, K. Development of a new commercialscale airlift fermentor for rapid growth of yeast. J . Ferment. Biotechnol. 1993, 75, 375-379.

(24) Austriaco, N. R. Review: To bud until death: The genetics of aging in the yeast, Saccharomyces. Yeast 1996, 12, 623630.

Accepted for publication December 22, 2000.

BP000164J 